\title{
Zs Research Suare \\ Cancer-Related Fatigue On Daily Living Activities in Pediatric Cancer Survivors
}

Müberra Tanrıverdi

Bezmialem Vakif University: Bezmialem Vakif Universitesi

Fatma Betül Çakır ( $\nabla$ fbetulcakir@gmail.com )

Bezmialem Vakif Universitesi Tip Fakultesi https://orcid.org/0000-0001-9581-8128

\section{Research Article}

Keywords: children, daily living activities, fatigue, pediatric cancer, survivorship

Posted Date: August 12th, 2021

DOl: https://doi.org/10.21203/rs.3.rs-726556/v1

License: (a) (i) This work is licensed under a Creative Commons Attribution 4.0 International License. Read Full License 


\section{Abstract}

Aim

Cancer-related long term complications such as cardiovascular disease, fatigue, weight-related problems, and emotional disturbances are found to be increased in pediatric cancer survivors (PCS). The relationship between daily living activities (DLA) and such complications is still being investigated. Our aim in this study was to investigate the impact of cancer-related fatigue on DLA in PCS.

\section{Methods}

Cancer-related fatigue was assessed by "PedsQL Multidimensional Fatigue Scale (MFS)”, "Visuel Analogue Scale (VAS)" and "Borg Fatigue Scale". The DLA was evaluated by WeeFIM.

\section{Results}

There were 77 PCS (44 boys) with a mean age of $10.76 \pm 4.49$ years. The mean value of fatigue scales were VAS $2.48 \pm 1.48$, Borg $0.61 \pm 1.00$ and MFS total score $71.14 \pm 18.74$. There was a statistically significant negative relationship between age and VAS scores of PCS ( $p=0.047)$. The girls were found more tired than boys (VAS; $p=0.031$ ). A positive correlation was established between the type of tumor and MFS total score $(p=0.048)$. WeeFIM total result was 118.64 \pm 11.37 . While there was a statisticially significant relationship between VAS Fatigue Score and WeeFIM total $(p=0.07)$, there was no such correlation between MFS total and WeeFIM total $(p=0.080)$ and Borg Fatigue Scale and WeeFIM total $(p=0.449)$.

\section{Conclusions}

It is established that there is a relationship between level of fatigue and DLA. Risk factors like tumor type or treatment modalities for fatigue should be investigated in larger samples of specific survivor groups. Fatigue and its association with DLA should be screened clinically as a routine surveillence in PCS and treatment options be planned.

\section{Introduction}

Fatigue is a distressing symptom which is one of the most common complaints of children with cancer [1]. High rates of physical impairment and lower physical functioning are the possible risk factors for fatigue. However, no definite reasons are established [2]. Indeed, pediatric and young adult cancer survivors suffer from cancer-related fatigue even years after completion of treatment due to mostly fear of recurrence and other reasons [3]. Parents and health care providers of pediatric cancer survivors (PCS) report that sleep changes, anxiety and side effects of medications used during cancer treatment might also cause fatigue [4]. The national comprehensive cancer network of USA defined cancer-related fatigue as "a distressing, persistent, subjective sense of physical, emotional and/or cognitive tiredness or exhaustion related to cancer or cancer treatment that is not proportional to recent activity and interferes with usual functioning" [5]. Therefore fatigue often might probably have detrimental effects on daily living activities (DLA). It has negative impacts on many aspects such as personal relationships and school/ work in PCS [6]. Fatigue, poor physical status and impaired functional mobility are among the most commonly reported long-term sequela of pediatric cancer treatment [7]. Emotional distress, pain, and physical functioning limitations were all associated with increased level of fatigue in another survivorship study [8]. Decreased physical fitness as a result of sequela of cancer treatment can cause DLA [4]. Many scales with symptom-related items have been developed to assess DLA in PCS [9].

Our primary goal was to evaluate cancer-related fatigue and its association with different types of measurements and second goal was to investigate the effect of fatigue on DLA in PCS. This study addresses a knowledge gap in the literature by exploring the level of impact of fatigue on DLA in PCS.

\section{Methods}

A quasiexperimental design was used to evaluate the feasibility and efficacy of fatigue on DLA in PCS. This study was approved by an Institutional Ethical Commity review board and research council at the affiliated clinical site.

\section{Participants}

Participants were recruited consecutively as part of the assessment at a tertiary pediatric hematology and oncology clinic, between 2018 and 2020 in a regular outpatient clinics examination. Before referral to the unit, patients had been throughly examined by their primary care physician in order to exclude any other causes for the symptoms. After referral, consent forms and questionnaires were applied to the patients when they visit the clinic. In total 77 patients completed both consent forms and questionnaires. The children who were referred from pediatric hematology and oncology to physiotherapy rehabilitation department were included in the study.

\section{Inclusion Criterias}

- 6-18 years of age

- Ability to walk independently in the community

- Parental consent to participate 


\section{Exclusion Criterias}

- Have an orthopedic and/or neurologic problem

- Not volunteer

- $<6$ and $>18$ years of age

\section{Measurements}

Background variables: Children background information included demographical data such as age, gender, and age at diagnosis and clinical characteristics of the illness.

PedsQL Multidimensional Fatigue Scale: The 18-item PedsQL ${ }^{\mathrm{TM}}$ Multidimensional Fatigue Scale (MFS) reflects three subscales: general fatigue, sleep/rest fatigue, and cognitive fatigue. The participants rated how often a particular problem occurred in the past month, using a 5-point Likert scale and for the young child self-report a 3-point scale. Each item is reverse-scored and rescaled to 0-100 scale, so that higher scores indicate fewer symptoms of fatigue [10].

Visual Analog Scale: The visual analog scale (VAS) is a valid and reliable measure, a tool with a 10-cm ruler and a marker that the patient moves to the point indicating his or her intensity were asked to rate pain intensity by placing a mark on a 100-mm VAS. The VAS was horizontally positioned with the extremes labeled " $0=$ least possible fatigue" and " $10=$ worst possible fatigue" [11].

Borg Fatigue Scale: Fatigue perception were determined using a 10 point modified Borg Scale during the walking test. Before the test at rest, the results of Perception of Dyspnea (Modified Borg Scale 0-10) and Perception of Fatique (Modified Borg Scale 0-10) value [12]. High scores indicate high level fatigue. The baseline values were used in our study.

WeeFIM: The Functional Independence Measure (FIM), builds on the organizational format of the Functional Independence Measure for Adults of the UDS for Medical Rehabilitation developed by Granger and colleagues, and the WeeFIM was modified for the children. The WeeFIM consists of 18 items involving six domains (self care, sphincter control, transfers, locomotion, communication, social cognition) for the children. In scoring the WeeFIM, a seven-level ordinal scale is used. Levels 6 and 7 reflect independence. No personal assistance is required by the child to successfully complete the task. However, level 6 , modified independence, reflects the child's need for an assistive device (e.g., brace, wheelchair, grab bar), additional time to complete task, or concerns about safety in order to complete the task. Levels 3,4 , and 5 require modified dependence; either supervision or a degree of personal assistance is required to complete the task. Levels 2 and 1 indicate complete dependence; a score of 2 indicates maximal assistance (i.e., the child's need for the adult to perform the majority of the task); a score of 1 is given when the caretaker performs almost all the task for the child. The total score is the sum of all items. The motor total score was consisted of self care, sphincter control, transfers, and locomotion. The cognitive total score was included communication and social cognition [13].

\section{Statistical Analysis}

SPSS software version 23.0 was used to analyze data. Student's t-test was used for discrimination analysis between groups after testing the ratio of the variances with an f-test and correcting the t-score according to the Smith-Satterthwaite method where appropriate. A confidence level of $p<0.05$ was considered statistically significant for reaching a statistical decision. Possible dependencies between outcome measures were investigated by computing Pearson's linear correlation coefficient " $r$ ". Detected correlations were deemed as "strong" if $r \geq 0.70$, "moderate" if $0.30 \leq r<0.70$, and "weak" if $r>0.30$. Correlation confidence levels were determined with one-tailed Student's t-test of the $r^{2}$ value.

\section{Results}

\section{Sample characteristics}

In this cross-sectional chart review study, data were analyzed regarding 77 PCS. Demographic characteristics were presented in Table 1. Their mean age was 10.76 (min-max $=6-18$ ) years with $44(57.1 \%)$ boys. The correlation analysis of demographic and clinical characteristics were given in Table 2 . There was a statistically significant negative relationship between age and VAS scores of PCS $(r=-0.288 ; p=0.047)$. Younger children were found to be more tired. The girls were found more tired than boys (VAS; $r=-0.433 ; p=0.031$ ). The mean age of them at diagnosis was $7.14(\mathrm{SD}, 4.20)$ years. The evalution was carried out with a mean age of 3.5 years after the end of the treatment. According to the body mass index (BMI) results of PCS, there was a positive correlation between BMI with VAS scores $(r=-0.397 ; p=0.049)$, and negative correlation between BMI with BORG scores $(r=0.322 ; p=0.048)$. The distribution of the types of cancer in decreasing frequency was, $n=32(41.6 \%)$ with the diagnosis of central nervous system tumor (CNS), 27 (35.1\%) acute lymphoblastic leukemia (ALL), 6 (7.8\%) lymphoma, 5 (6.5\%) soft tissue sarcoma, $3(3.9 \%)$ neuroblastoma, 3 (3.9\%) Wilms tumor, and 1 (1.3\%) bone tumor. There was a positive correlation between the type of tumor and MFS total score $(r=0.322 ; p=0.048)$. Fourty-two $(54.5 \%)$ of them had either chemotherapy (CT), or radiotherapy (RT) or surgery. The average length of cancer treatment was $28.35 \pm 11.27$ (min-max $=2-53$ ) months. CT cycles of 7.27 (SD, 3.66), and RT sessions of 31.27 (SD, 9.06 ) were received. Thirty of the families (38.9\%) were consanguineous marriages. Considering the educational status, 43 (55.8\%) of the mothers and 27 ( $35.1 \%)$ of the fathers were primary school graduates. 
Table 1

The results of the demographic-clinical features, fatigue and daily living activities of children with total group and Brain Tumor vs Acute Lymphoblastic Leukemia subgroups

\begin{tabular}{|c|c|c|c|c|c|c|}
\hline & \multicolumn{3}{|c|}{ Total Group ( $\mathrm{N}=77)$} & \multicolumn{2}{|l|}{ Subgroups } & \multirow[t]{3}{*}{$p$} \\
\hline & & & & CNS Group ( $=32)$ & ALL Group ( $N=27)$ & \\
\hline & Mean \pm SD & Min & Max & Mean \pm SD & Mean \pm SD & \\
\hline Age (years) & $10.76 \pm 4.48$ & 6 & 18 & $9.81 \pm 3.71$ & $13.53 \pm 4.94$ & $0.005^{\star \star}$ \\
\hline Body Mass Index (BMI) & $17.90 \pm 3.54$ & 12.20 & 29.59 & $17.83 \pm 3.15$ & $17.75 \pm 3.20$ & 0.935 \\
\hline Academic achievement $[0-10]^{\dagger}$ & $6.88 \pm 3.17$ & 0 & 10 & $6.23 \pm 3.54$ & $7.50 \pm 2.38$ & 0.498 \\
\hline Age at diagnosis (years) & $7.14 \pm 4.19$ & 1 & 16 & $7.29 \pm 3.96$ & $7.00 \pm 5.40$ & 0.845 \\
\hline Chemotherapy cycle number & $7.27 \pm 3.65$ & 0 & 21 & $7.30 \pm 2.90$ & $4.60 \pm 2.61$ & 0.060 \\
\hline Radiotherapy session number & $31.27 \pm 9.05$ & 0 & 46 & $32.18 \pm 8.54$ & - & - \\
\hline \multicolumn{7}{|l|}{ Fatigue } \\
\hline Visuel Analog Scale (VAS) Fatigue [0-10] ${ }^{\natural}$ & $2.48 \pm 1.48$ & 1 & 7 & $3.27 \pm 1.52$ & $1.38 \pm 0.81$ & $0.000 * \star$ \\
\hline Borg Fatigue [0-10] 9 & $0.61 \pm 1.00$ & 0 & 4 & $0.67 \pm 1.16$ & $0.38 \pm 0.69$ & 0.501 \\
\hline MFS Total Fatigue $[0-100]^{\dagger}$ & $71.14 \pm 18.74$ & 34.72 & 100 & $67.03 \pm 18.94$ & $71.96 \pm 18.06$ & 0.420 \\
\hline MFS General Fatigue $[0-100]^{\dagger}$ & $71.83 \pm 19.60$ & 29.16 & 100 & $67.57 \pm 21.50$ & $72.13 \pm 18.92$ & 0.498 \\
\hline MFS Sleep/Rest Fatigue [0-100] ${ }^{\dagger}$ & $68.58 \pm 21.04$ & 25 & 100 & $65.39 \pm 21.26$ & $69.01 \pm 15.44$ & 0.565 \\
\hline MFS Cognitive Fatigue $[0-100]^{\dagger}$ & $72.99 \pm 26.31$ & 12.50 & 100 & $68.11 \pm 26.96$ & $74.74 \pm 28.07$ & 0.463 \\
\hline \multicolumn{7}{|l|}{ WeeFIM } \\
\hline Self care $[6-42]^{\dagger}$ & $38.44 \pm 6.13$ & 13 & 42 & $36.26 \pm 7.63$ & $40.19 \pm 4.43$ & 0.072 \\
\hline Sphincter control $[2-14]^{\dagger}$ & $13.64 \pm 1.49$ & 4 & 14 & $13.65 \pm 0.78$ & $13.38 \pm 2.50$ & 0.620 \\
\hline Transfers $[3-21]^{\dagger}$ & $20.08 \pm 1.79$ & 12 & 21 & $19.74 \pm 1.66$ & $20.25 \pm 2.32$ & 0.427 \\
\hline Locomotion $[2-14]^{\dagger}$ & $13.54 \pm 1.03$ & 9 & 14 & $13.13 \pm 1.39$ & $13.88 \pm 0.34$ & $0.044^{\star}$ \\
\hline Communication $[2-14]^{\dagger}$ & $13.38 \pm 1.65$ & 6 & 14 & $13.04 \pm 1.75$ & $13.94 \pm 0.25$ & $0.050^{*}$ \\
\hline Social cognition $[3-21]^{\dagger}$ & $19.58 \pm 2.73$ & 10 & 21 & $18.52 \pm 3.27$ & $20.81 \pm 0.54$ & $0.009 * *$ \\
\hline Motor control total [13-91] ${ }^{\dagger}$ & $85.70 \pm 8.80$ & 56 & 91 & $82.78 \pm 9.78$ & $87.69 \pm 8.97$ & 0.120 \\
\hline Cognitive total $[5-35]^{\dagger}$ & $32.96 \pm 4.18$ & 18 & 35 & $31.57 \pm 4.73$ & $34.75 \pm 0.78$ & $0.011^{\star}$ \\
\hline Total $[18-126]^{\dagger}$ & $118.64 \pm 11.37$ & 86 & 126 & $114.30 \pm 13.21$ & $122.44 \pm 8.92$ & $0.039 *$ \\
\hline
\end{tabular}


Table 2

The relationship between the demographic-clinical features and fatigue in pediatric cancer survivors

\begin{tabular}{|c|c|c|c|c|c|c|c|}
\hline$N=77$ & & $\begin{array}{l}\text { VAS } \\
\text { Fatigue }\end{array}$ & $\begin{array}{l}\text { BORG } \\
\text { Fatigue }\end{array}$ & $\begin{array}{l}\text { MFS Total } \\
\text { Score }\end{array}$ & $\begin{array}{l}\text { MFS General } \\
\text { Score }\end{array}$ & $\begin{array}{l}\text { MFS Sleep/rest } \\
\text { Score }\end{array}$ & $\begin{array}{l}\text { MFS Cognitive } \\
\text { Score }\end{array}$ \\
\hline \multirow[t]{2}{*}{ Age } & z & $-0.288^{*}$ & -0.221 & -0.007 & -0.248 & -0.122 & -0.015 \\
\hline & $\mathrm{p}$ & 0.047 & 0.160 & 0.974 & 0.231 & 0.562 & 0.943 \\
\hline \multirow[t]{2}{*}{ Gender } & z & $-0.433^{\star}$ & 0.299 & 0.120 & -0.014 & -0.390 & -0.327 \\
\hline & $\mathrm{p}$ & 0.031 & 0.147 & 0.567 & 0.948 & 0.054 & 0.110 \\
\hline \multirow[t]{2}{*}{ Body mass index (BMI) } & z & $-0.397 *$ & $0.322^{\star}$ & 0.074 & -0.126 & -0.075 & 0.158 \\
\hline & $\mathrm{p}$ & 0.049 & 0.048 & 0.727 & 0.547 & 0.720 & 0.450 \\
\hline \multirow[t]{2}{*}{ Type of tumor } & z & 0.279 & -0.231 & $0.317^{*}$ & 0.186 & 0.067 & 0.153 \\
\hline & $\mathrm{p}$ & 0.128 & 0.196 & 0.025 & 0.195 & 0.644 & 0.289 \\
\hline \multirow[t]{2}{*}{ Radiotherapy session number } & z & $0.610^{* *}$ & 0.125 & 0.010 & 0.168 & 0.282 & -0.043 \\
\hline & $\mathrm{p}$ & 0.001 & 0.561 & 0.961 & 0.421 & 0.172 & 0.837 \\
\hline \multirow[t]{2}{*}{ Chemotherapy cycle number } & z & 0.223 & $-0.588^{* *}$ & 0.094 & -0.119 & -0.121 & -0.231 \\
\hline & $\mathrm{p}$ & 0.284 & 0.002 & 0.654 & 0.572 & 0.566 & 0.267 \\
\hline \multirow{2}{*}{$\begin{array}{l}\text { Consanguineous marriage of } \\
\text { parents }\end{array}$} & z & 0.415 & -0.028 & 0.078 & 0.193 & 0.099 & 0.254 \\
\hline & $\mathrm{p}$ & 0.307 & 0.943 & 0.592 & 0.180 & 0.495 & 0.075 \\
\hline
\end{tabular}

\section{Measurements}

The descriptive results of fatigue measurements (MFS total, MFS general, MFS sleep/rest, MFS cognitive, VAS, Borg) and DLA scale called WeeFIM (self care, sphincter control, transfers, locomotion, communication, social cognition, motor total, cognitive total and total) were presented in Table 1. The mean values of DLA measured by WeeFIM was 118.64 (SD, 11.37). A significant correlation was found between RT and VAS fatigue score $(r=0.610 ; p=0.001)$. We found that there was a significant relationship between CT and BORG fatigue score $(r=-0.588 ; p=0.002)$.

The majority of our study consisted of patients with CNS ( $N=32 ; 41.6 \%$, mean age $=9.81 \pm 3.71$ years) and $A L L(N=27 ; 35.1 \%$, mean age $=13.53 \pm 4.94$ years). There was a statistically significant difference between the ages of children with ALL and CNS $(p=0.005)$. The average length of cancer treatment was $14.25 \pm 4.67$ months in CNS group, and $40.23 \pm 15.84$ months in ALL group. The fatigue (VAS, BORG, MFS) and WeeFIM scale results of PCS as total group (N = 77), CNS group ( $N=32)$ and ALL group ( $N=27)$ were given in Table 1. The evaluation was carried out after 38 months in ALL group and 15 months in CNS group $(p<0.05)$ after the end of the treatment. CNS group was found to be significantly more tired than ALL group $(V A S ; C N S$ vs ALL = 3.27 vs $1.38 ; p=0.000)$ (Fig. 1). According to Borg and MFS scores, there was no statistically significant difference between groups, but CNS group was more tired in terms of all scale scores. Some of WeeFIM scores in CNS group were significantly lower than the ALL group (Table 1). While there was a statistically significant difference between WeeFIM locomotion ( $p=0.044)$, communication $(p=0.050)$, social cognition $(p=0.009)$ subheadings and cognitive total $(p=0.011)$ and total scores $(p=0.039)$, there was no statistically significant difference between self care $(p=0.039) .=0.072)$, sphincter control $(p=0.620)$, transfers $(p=0.427)$ subheadings and motor total $(p=0.120)$ scores between CNS group and ALL group (Table 1 \& Fig. 2).

\section{Correlations}

Hierarchical linear regression was conducted to determine the demographic and cancer related variables. Correlation between fatigue and DLA in PCS was given in Table 3. There was statistically significant correlation between VAS fatigue score and WeeFIM total scores $(r=-0.387 ; p=0.007)($ Table 3$)$ in all study sample. 
Table 3

The correlation between fatigue and daily living activities in pediatric cancer survivors

\begin{tabular}{|c|c|c|c|c|c|c|c|c|c|c|c|c|}
\hline \multirow[t]{2}{*}{$N=77$} & & & & \multicolumn{9}{|l|}{ WeeFIM } \\
\hline & & & & $\begin{array}{l}\text { Self } \\
\text { care }\end{array}$ & $\begin{array}{l}\text { Sphincter } \\
\text { control }\end{array}$ & Transfers & Locomotion & Communication & $\begin{array}{l}\text { Social } \\
\text { cognition }\end{array}$ & $\begin{array}{l}\text { Motor } \\
\text { control } \\
\text { subscale }\end{array}$ & $\begin{array}{l}\text { Cognitive } \\
\text { subscale }\end{array}$ & $\begin{array}{l}\text { Total } \\
\text { score }\end{array}$ \\
\hline \multirow[t]{12}{*}{ Fatigue } & \multirow{2}{*}{\multicolumn{2}{|c|}{ VAS }} & $z$ & $-0.393^{\star \star}$ & -0.013 & -0.094 & -0.221 & -0.277 & -0.398 ** & $-0.321^{\star}$ & $-0.369 * \star$ & -0.387 ** \\
\hline & & & $\mathrm{p}$ & 0.006 & 0.931 & 0.525 & 0.130 & 0.056 & 0.005 & 0.026 & 0.010 & 0.007 \\
\hline & \multirow{2}{*}{\multicolumn{2}{|c|}{ BORG }} & z & -0.037 & 0.035 & 0.091 & -0.208 & $-0.328 *$ & -0.144 & -0.038 & -0.225 & -0.120 \\
\hline & & & $\mathrm{p}$ & 0.815 & 0.827 & 0.567 & 0.187 & 0.034 & 0.361 & 0.810 & 0.152 & 0.449 \\
\hline & \multirow[t]{8}{*}{ MFS } & \multirow[t]{2}{*}{ General } & $z$ & 0.193 & 0.065 & 0.007 & $0.338^{*}$ & 0.235 & $0.376^{\star \star}$ & 0.186 & $0.338^{*}$ & 0.270 \\
\hline & & & $\mathrm{p}$ & 0.180 & 0.655 & 0.960 & 0.016 & 0.101 & 0.007 & 0.195 & 0.016 & 0.058 \\
\hline & & \multirow{2}{*}{$\begin{array}{l}\text { Rest } \\
\text { sleep }\end{array}$} & $z$ & 0.067 & 0.006 & -0.020 & 0.170 & -0.002 & 0.199 & 0.064 & 0.129 & 0.099 \\
\hline & & & $\mathrm{p}$ & 0.644 & 0.966 & 0.891 & 0.237 & 0.990 & 0.166 & 0.660 & 0.371 & 0.495 \\
\hline & & \multirow[t]{2}{*}{ Cognitive } & $z$ & $0.286^{\star}$ & 0.163 & 0.139 & -0.009 & -0.008 & 0.239 & 0.254 & 0.153 & 0.254 \\
\hline & & & $\mathrm{p}$ & 0.044 & 0.258 & 0.337 & 0.948 & 0.958 & 0.095 & 0.075 & 0.289 & 0.075 \\
\hline & & \multirow[t]{2}{*}{ Total } & $z$ & 0.226 & 0.101 & 0.060 & 0.177 & 0.078 & $0.317^{*}$ & 0.208 & 0.238 & 0.250 \\
\hline & & & $\mathrm{p}$ & 0.115 & 0.485 & 0.679 & 0.219 & 0.592 & 0.025 & 0.148 & 0.096 & 0.080 \\
\hline
\end{tabular}

VASVisuel Analog Scale, MFSPedsQL Multidimensional Fatigue Scale, Pearson correlation analysis * $p<0.05, * x<0.01$

\section{Discussion}

This study examines the association between symptoms of fatigue and DLA and evaluates their relationships in terms of subgroups in PCS. The results of scales were evaluated as VAS, Borg and PedsQL MFS; and DLA with WeeFIM.

According to our results, the important risk factors affecting fatigue were; age, gender, BMI, tumor type, time after completion of treatment, CT and RT. Younger age was found to be associated with higher level of fatigue. We cannot definitely find out the reason, but this is probably due to presence of large sample size of children with CNS tumor in whom their ages were younger than the leukemia group; becouse it is established that patients with CNS tumors were more tired than ALL group in our study. We did not find an association between age at diagnosis and fatigue in our study like that of the [14-16]. Girls had high fatigue scores in our study. This is also probably related to the larger sample of CNS group in our study. This demographic finding was consistent with other various studies [14-18]. Higher BMI was associated with higher levels of fatigue in our study. Although Karimi et al. [4], having a sample of recent survivors like that of us did not report such association, Johnson et al. [19] reported clinically significant relationship with fatigue and weight. This study included brain tumor survivors of ages 8-12 years who were less than 6 years posttreatment, that is like our brain tumor study group. Studies with adult survivors of childhood cancers revealed an increased risk of fatigue with higher BMI [7, 14]. Time after completion of treatment was $28.35 \pm 11.27$ months in our study. Our study time point was relatively an earlier time after completion of treatment than that of the literature, but our findings are in concordant with Johnson et al. [19], Karimi et al. [4], and Nagai et al [17]. in which those studies are also the studies performed just recent years after treatment. Fatigue scores decreased with time elapsed in those studies. According to our study, in terms of CNS vs ALL group, probably because ALL group was older in age and a longer period of time had passed since the end of the treatment, a lower level of fatigue was detected in that ALL group. The average time since diagnosis was under 10 years in our study and those aformentioned studies [4,17, 19]. This is a shorter time than that of Langeveld et al. [15], Meeske et al. [7] and Mulroney et al [14] in which fatigue levels declined over time during the long follow up of survivors. Tumor type, in our study, which indicates high number of patients with CNS tumor ( $40 \%$ of total) was found to be associated with higher fatigue scores. Johnson et al. [19], pointed the significance of fatigue in their brain study group of 21 patients. However, no significant effect was found between fatigue and primary cancer diagnosis in the literature. [4, 14-18]. Treatment modalities of both CT and RT were found to be significantly associated with higher levels of fatigue in this study. This might be probably due to large sample size of patients with CNS tumors in our study in whom all of them were treated with both CT and cranial RT. Johnson et al. [19] established a clinically significant relationship between fatigue and CT and cranial RT. Forty-two of 142 (30\%) CNS tumor survivors were identified as having clinically significant fatigue in the study of Brand's et al [20]. Although an increased risk was detected with any RT $[4,15,16,18]$, there is conflicting evidence of the risk after cranial irradiation [15-17]. In contrary to our findings, no significant effect of CT was found in the literaure $[4,14,16,18]$. The International Late Effects of Childhood cancer guideline harmonization group (IGHG), in 2020, graded the strength of the fatigue recommendations according to published evidence-based methods [3] and reported that survivors are at increased risk for cancer-related fatigue (Level A evidence). They found the prevalance of fatigue ranging from 10.2 to $85 \%$ in 24 studies.

After measurement of fatigue in our study, we investigated the outcome of fatigue in cancer survivors in terms of impact on quality of life, mobility, self-care, locomotion, communication and cognition. Many studies used and recommended the scales which called PROMIS Pediatric Fatigue Measure and PedsQL MFS [21-25] in children with cancer. It is suggested that PROMIS pediatric fatigue measures, and the PedsQL MFS are valid and reliable measures to evaluate fatigue in patients with cancer (level B) [3]. In our study, we used PedsQL MFS which correlated the fatigue scales significantly. We found a statistically significant relationship between VAS score and WeeFIM self-care, social cognition, motor control, cognitive and total control. WeeFIM total, cognitive and motor total score average was found at "modified independence" level. Although these children perform no-help activities in DLA, they are not at completely 
"independent-complete independence" level. This shows that their levels are below the levels of healthy normal children [26]. It was seen that not only physical but also mental fatigue of children was reflected in their DLA. Patients with higher VAS scores (high fatigue score) did low performance of WeeFim self-care, social cognition, motor control, cognitive and total control. Patients with high MFS scores (low fatigue scores) had high performance in locomotion, social cognition and cognitive subscale. We found higher scores of fatigue in CNS tumor group than ALL group, in our study, and there was a significant association in terms of WeeFIM locomotion, communication, cognition, but not with sphincter control, transfers and motor total between these groups. CNS tumor group, with younger ages and having high risk of neurocognitive sequela due to surgery, cranial RT and CT, showed low WeeFim scores on communication and cognition. Hence, fatigue has not only physical impact but also neurocognitive adverse effect. DLA are more hampered in patients with CNS tumor in terms of self-care, socialization and cognition rather than locomotion. These results indicate that symptom profiles may be important to understand the variation between individuals in terms of impact of symptoms on functioning.

Our study has several clinical implications and limitations. First, PCS attending pediatric oncology centers should be screened for fatigue and would benefit from routine assessment of fatigue. Risk factors according to each patient should be identified and possible physical, social and cognitive impact should be screened by way of measurements of DLA. There should be interventions and solutions in management of symptoms of fatigue after ruling out other medical reasons. Given our study on self-reported data, information about past/current symptoms and other medical information may have been affected by recall bias. This study is cross-sectional with a wide age range of patients with heterogeinity. However, we suggest survivors with CNS tumor needs more attention and care in terms of fatigue and its outcome.

Future cohort studies with specific and detailed evaluations are needed to improve surveillance and/or screening for fatigue, and mobility and of potential relevances like the maintenance of overweight. Future studies may benefit from assessments of symptomatic treatments according to tumor types. Christen et al. [3] mentioned that interventions that are useful are physical activity (level B evidence), education about cancer-related fatigue (level B evidence), relaxation and mindfullness (level $\mathrm{C}$ evidence, existing guidelines), cognitive behavioral therapy (level C evidence, existing guidelines), and adventure-based training (level $\mathrm{C}$ evidence). Growing evidence advocates physical activity interventions as beneficial, as well as feasible and safe, in managing cancer-related fatigue, and also improve quality of life and functional status during and after treatment in PCS [27].

\section{Conclusion}

In conclusion, fatigue is frequently experienced as a late effect of PCS. Particularly survivors with CNS tumor needs attention and follow-up. The study suggests that clinical physiotherapy rehabilitation evaluation might be successfully used in PCS in determining and treatment of fatigue.

\section{Declarations}

Funding: N/A

Conflict of interest/Competing interests: No conflict of interest.

Availability of data and material: Dataset can be made available from the authors pending appropriate authorisations.

\section{Code availability: N/A}

Authors' contributions: Conceptualization: [Müberra Tanrıverdi], [Fatma Betül Çakır]; Methodology: [Müberra Tanrıverdi], [Fatma Betül Çakır]; Formal analysis and investigation: [Müberra Tanrıverdi], [Fatma Betül Çakır]; Writing-original draft preparation: [[Müberra Tanrıverdi], [Fatma Betül Çakır]; Writing - review and editing: [Müberra Tanrıverdi], [Fatma Betül Çakır]; Funding acquisition: [Müberra Tanrıverdi], [Fatma Betül Çakır]; Resources: [Müberra Tanrıverdi], [Fatma Betül Çakır]; Supervision: [Müberra Tanrıverdi], [Fatma Betül Çakır]

Ethical approval The study was approved by the Bezmialem Vakıf University Non-Interventional Research Ethics Committee (01/2018 dated, and with the approval number of 2011-KAEK-42-1/13)

Consent to participate Informed consent was requested from all eligible patients and parents and obtained from all participants.

\section{Consent for publication: N/A}

\section{References}

1. Keener AT (2019) Childhood Cancer-related fatigue and day-to-day quality of life. J Pediatr Oncol Nurs 36(2):74-85. https://doi.org/10.1177/1043454218818062

2. Kelada L, Wakefield CE, Heathcote LC et al (2019) Perceived cancer-related pain and fatigue, information needs, and fear of cancer recurrence among adult survivors of childhood cancer. Patient Educ Couns 102(12):2270-2278. https://doi.org/10.1016/j.pec.2019.06.022

3. Christen S, Roser K, Mulder RL et al (2020) Recommendations for the surveillance of cancer-related fatigue in childhood, adolescent, and young adult cancer survivors: a report from the International Late Effects of Childhood Cancer Guideline Harmonization Group. J Cancer Surviv 1-16.

https://doi.org/10.1007/s11764-020-00904-9

4. Karimi M, Cox AD, White SV, Karlson CW (2020) Fatigue, physical and functional mobility, and obesity in pediatric cancer survivors. Cancer Nurs 43(4):E239-E245. https://doi.org/10.1097/NCC.0000000000000712 
5. Berger AM, Abernethy AP, Atkinson A et al (2010) NCCN Clinical Practice Guidelines Cancer-related fatigue. J Natl Compr Canc Netw 8(8):904-931. https://doi.org/10.6004/jnccn.2010.0067

6. Jóhannsdóttir IM, Hjermstad MJ, Moum T et al (2012) Increased prevalence of chronic fatigue among survivors of childhood cancers: a population-based study. Pediatr Blood Cancer 58(3):415-420. https://doi.org/10.1002/pbc.23111

7. Meeske KA, Siegel SE, Globe DR, Mack WJ, Bernstein L (2005) Prevalence and correlates of fatigue in long-term survivors of childhood leukemia. J Clin Oncol 23(24):5501-5510. https://doi.org/10.1200/JC0.2005.03.210

8. Rach AM, Crabtree VM, Brinkman TM et al (2017) Predictors of fatigue and poor sleep in adult survivors of childhood Hodgkin's lymphoma: a report from the Childhood Cancer Survivor Study. J Cancer Surviv 11(2):256-263. https://doi.org/10.1007/s11764-016-0583-y

9. Cox CL, Sherrill-Mittleman DA, Riley BB et al (2013) Development of a comprehensive health-related needs assessment for adult survivors of childhood cancer. J Cancer Surviv 7(1):1-19. https://doi.org/10.1007/s11764-012-0249-3

10. Varni JW, Burwinkle TM, Katz ER, Meeske K, Dickinson P (2002) The PedsQL ${ }^{T M}$ in pediatric cancer: reliability and validity of the pediatric quality of life inventory ${ }^{\text {TM }}$ generic core scales, multidimensional fatigue scale, and cancer module. Cancer 94(7):2090-2106. https://doi.org/10.1002/cncr.10428

11. Scott J, Huskisson EC (1979) Vertical or horizontal visual analogue scales. Ann Rheum Dis 38(6):560. https://doi.org/10.1136/ard.38.6.560

12. Wilson RC, Jones PW (1989) A comparison of the visual analogue scale and modified Borg scale for the measurement of dyspnoea during exercise. Clin Sci 76(3):277-282. https://doi.org/10.1042/cs0760277

13. Msall ME, DiGaudio K, Rogers BT et al (1994) The Functional Independence Measure for Children (WeeFIM) conceptual basis and pilot use in children with developmental disabilities. Clin Pediatr 33(7):421-430. https://doi.org/10.1177/000992289403300708

14. Mulrooney DA, Ness KK, Neglia JP et al (2008) Fatigue and sleep disturbance in adult survivors of childhood cancer: a report from the childhood cancer survivor study (CCSS). Sleep 31(2):271-281. https://doi.org/10.1093/sleep/31.2.271

15. Langeveld N, Stam H, Grootenhuis M, Last B (2002) Quality of life in young adult survivors of childhood cancer. Support Care Cancer 10(8):579-600. https://doi.org/10.1007/s00520-002-0388-6

16. Frederick NN, Kenney L, Vrooman L, Recklitis CJ (2016) Fatigue in adolescent and adult survivors of non-CNS childhood cancer: a report from project REACH. Support Care Cancer 24(9):3951-3959. https://doi.org/10.1007/s00520-016-3230-2

17. Nagai A, Zou N, Kubota M et al (2012) Fatigue in survivors of childhood acute lymphoblastic and myeloid leukemia in Japan. Pediatr Int 54(2):272-276. https://doi.org/10.1111/j.1442-200X.2011.03530.x

18. Mört S, Lähteenmäki PM, Matomäki J, Salmi TT, Salanterä S (2011) Fatigue in young survivors of extracranial childhood cancer: a Finnish nationwide survey. Oncol Nurs Forum 38(6). https://doi.org/10.1188/11.ONF.E445-E454

19. Johnson AH, Rodgers Phillips S, Rice M (2020) Abnormal weight gain with fatigue and stress in early survivorship after childhood brain tumor diagnosis. J Spec Pediatr Nurs 25(3):e12288. https://doi.org/10.1111/JSPN.12288

20. Brand SR, Chordas C, Liptak C, Manley P, Recklitis C (2016) Screening for fatigue in adolescent and young adult pediatric brain tumor survivors: accuracy of a single-item screening measure. Support Care Cancer 24(8):3581-3587. https://doi.org/10.1007/s00520-016-3150-1

21. Hinds PS, Nuss SL, Ruccione KS et al (2013) PROMIS pediatric measures in pediatric oncology: valid and clinically feasible indicators of patient-reported outcomes. Pediatr Blood Cancer 60(3):402-408. https://doi.org/10.1002/pbc.24233

22. Reeve BB, McFatrich M, Mack JW et al (2020) Expanding construct validity of established and new PROMIS Pediatric measures for children and adolescents receiving cancer treatment. Pediatr Blood Cancer 67(4):e28160. https://doi.org/10.1002/pbc.28160

23. Reeve BB, Edwards LJ, Jaeger BC et al (2018) Assessing responsiveness over time of the PROMIS $®$ pediatric symptom and function measures in cancer, nephrotic syndrome, and sickle cell disease. Qual Life Res 27(1):249-257. https://doi.org/10.1007/s11136-017-1697-z

24. Nascimento LC, Nunes MDR, Rocha EL et al (2015) High validity and reliability of the PedsQL ${ }^{\text {TM }}$ multidimensional fatigue scale for Brazilian children with cancer. J Pediatr Oncol Nurs 32(1):57-64. https://doi.org/10.1177/1043454214554656

25. Ye Q, Liu K, Wang J, Bu X, Zhao L (2016) Reliability and validity of the Chinese version of the PedsQL Multidimensional Fatigue Scale in children with acute leukemia. Int J Nurs Sci 3(2):146-152. https://doi.org/10.1016/j.jpnss.2016.04.001

26. Graham JE, Granger CV, Karmarkar AM et al (2014) The Uniform Data System for Medical Rehabilitation: report of follow-up information on patients discharged from inpatient rehabilitation programs in 2002-2010. Am J Phys Med Rehab 93(3):231. https://doi.org/10.1097/PHM.0b013e3182a92c58

27. Chang CW, Mu PF, Jou ST, Wong TT, Chen YC (2013) Systematic review and meta-analysis of nonpharmacological interventions for fatigue in children and adolescents with cancer. Worldv Evid-Based Nu 10(4):208-217. https://doi.org/:10.1111/wvn.1200

\section{Figures}




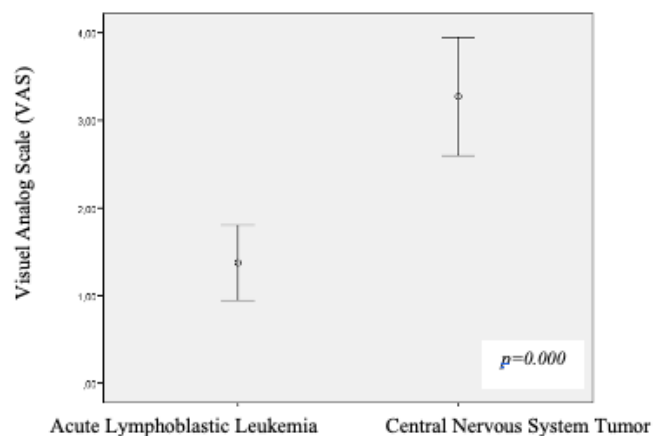

\section{Figure 1}

The evaluation was carried out after 38 months in ALL group and 15 months in CNS group $(p<0.05)$ after the end of the treatment. CNS group was found to be significantly more tired than ALL group (VAS; CNS vs ALL= 3.27 vs 1.38; $p=0.000$ ) (Figure 1).

\section{WeeFIM}

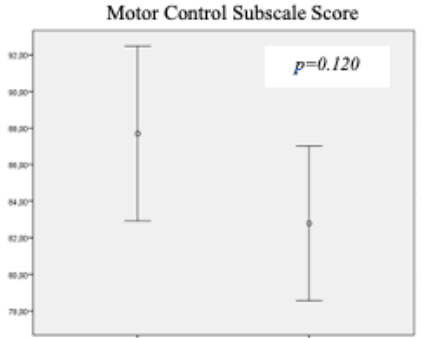

ALL
CNS

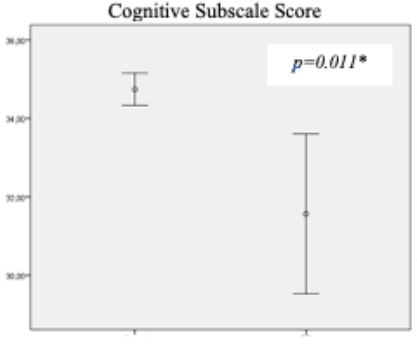

ALL

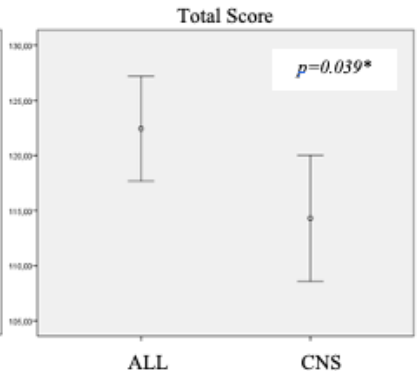

ALL

CNS

Figure 2

While there was a statistically significant difference between WeeFIM locomotion ( $p=0.044)$, communication $(p=0.050)$, social cognition ( $p=0.009)$ subheadings and cognitive total $(p=0.011)$ and total scores $(p=0.039)$, there was no statistically significant difference between self care $(p=0.039)$. $=0.072)$, sphincter control $(p=0.620)$, transfers $(p=0.427)$ subheadings and motor total $(p=0.120)$ scores between CNS group and ALL group (Table 1 \& Figure 2$)$. 